doi:10.4149/neo_2014_005

\title{
MicroRNA-191 correlates with poor prognosis of colorectal carcinoma and plays multiple roles by targeting tissue inhibitor of metalloprotease 3
}

\author{
S. QIN ${ }^{1}$, Y. ZHU' 2 , F. AI ${ }^{3}$, Y. $\mathrm{LI}^{1}$, B. BAI ${ }^{1}$, W. YAO ${ }^{4}$, L. DONG ${ }^{1, *}$ \\ ${ }^{1}$ Second General Surgery, The First Affiliated Hospital of Xinxiang Medical College, China; ${ }^{2}$ Infectious Disease, The First Affiliated Hospital of \\ Xinxiang Medical College, China; ${ }^{3}$ Pediatric Surgery, The First Affiliated Hospital of Xinxiang Medical College, China; ${ }^{4}$ Thoracic Surgery, The \\ First Affiliated Hospital of Xinxiang Medical College, China
}

${ }^{*}$ Correspondence: drdongliangpeng@126.com

Received January 28, 2013 / Accepted April 26, 2013

\begin{abstract}
MicroRNA-191 (miR-191) is reported to be overexpressed in colorectal carcinoma (CRC), but the role of miR-191 in CRC progress remained unclear. This study demonstrated that High miR-191 expression was associated with clinical stage, lymph node metastasis, liver metastasis and depth of tumor invasion. Kaplan-Meier analysis indicated that patients with high miR-191 expression had a poor overall survival. Moreover, multivariate analysis showed that miR-191 was an independent prognostic factor in patients with CRC. Furthermore, we found that tissue inhibitor of metalloprotease 3 (TIMP3) was a direct target of miR-191 in colorectal cancer SW620 cells. TIMP3 downregulation mediated by miR-191 activated matrix metalloproteinases (MMPs) and thus promoted invasiveness of cancer cells. Anti-miR-191 could attenuate the invasiveness, suppress proliferation and induce apoptosis by restoring TIMP3 expression. Our results suggested that miR-191 might be a potential diagnostic and therapeutic target in patients with colorectal cancer.
\end{abstract}

Key words: microRNA-191, colorectal carcinoma, prognosis, tissue inhibitor of metalloprotease 3

Colorectal carcinoma (CRC) remains one of the most common causes of cancer-related death worldwide as well as in China $[1,2]$. For most patients, liver metastasis from colorectal cancer is a leading cause of death [3]. The Tumor, Nodes, and Metastasis (TNM) staging system, is a commonly used method to classify CRC tumor [4], is inaccurate predicting the future outcome for each particular case because the tumor molecular biology is not considered sufficiently[5]. Therefore, the development of new biomarkers to facilitate early diagnosis, which may also help to improve post-operative treatment approaches for CRC patients, is an urgent need.

MicroRNAs (miRNAs), a class of small (19-25 nucleotide) non-coding RNAs, has been suggested to play important roles in tumorigenesis and cancer progression [6]. Compared with mRNA, miRNA may be more suitable for molecular marker because of its small size, stability, and resistance to RNase degradation [7]. In CRC, several miRNAs have been found to correlate with prognosis of patients [8-10]. Previous studies reported that miR-191 was upregulated in CRC $[11,12]$ and it could enhance cell proliferation, decreases apoptosis in hepatocellular carcinoma and in gastric carcinoma [13,
14]. However, the role of miR-191 in CRC progress and the relationship between the expression of $\mathrm{miR}-191$ and prognosis in patients remained unclear.

In this study, we analyzed the correlation of miR-191 expression with clinicopathologic factors and examined the mechanism. Our data show that high miR-191 expression was an independent prognostic factor associated with metastasis of CRC. Furthermore, miR-191 probably exerted its function by directly targeting Tissue Inhibitor of Metalloprotease 3 (TIMP3).

\section{Materials and methods}

Clinical tissue samples. A total of 136 patients who underwent resection of the primary CRC at The First Affiliated Hospital of Xinxiang Medical College between 2003 and 2008 were analyzed in this study. None of the patients received preoperative chemotherapy or radiotherapy. Resected tissue samples were obtained with informed consent and immediately frozen in liquid nitrogen until RNA extraction. All tumor specimens were histopathologically verified. Clinicopathologi- 
cal factors and clinical stage were classified using the criteria of the International Union against Cancer [4]. The study was approved by the medical ethics committee of Xinxiang Medical College.

Cell cultures. All cell lines were cultured in RPMI 1640 medium containing 10\% FBS (Gibco, Los Angeles, CA, USA) and were incubated at $37^{\circ} \mathrm{C}$ in a $5 \% \mathrm{CO}_{2}$ atmosphere. For anti-miR transfection, cells were plated in $60 \mathrm{~mm}$ dishes and transiently transfected with 60nM Anti-miR-191, or control anti-sense RNA (anti-NC) (Applied Biosystems, USA) by Lipofectamine RNAiMAX reagent (Invitrogen, Carlsbad, CA, USA). For rescue experiments, cells were transfected at $24 \mathrm{~h}$ after anti-miR transfection with 60nM TIMP3 siRNA or control siRNA (Santa Cruz, CA, USA) by supporting siRNA Transfection Reagent (Santa Cruz). Cells were assayed 24h after anti-miR or siRNA transfection.

Evaluation of miR-191 expression by realtime PCR. Total RNA was extracted from tumor tissue or cells with the mirVana miRNA isolation kit (Ambion, Austin, TX, USA) according to the manufacturer's instructions. cDNA was synthesized from $10 \mathrm{ng}$ of total RNA using Taq-Man MicroRNA Reverse Transcription kit (Applied Biosystems). Real-time PCR analyses were carried out using TaqMan miRNA assays and hsa-miR-191 specific primers (Applied Biosystems) according to the manual. The relative amount of miR-191 to RNU6B RNA was calculated using the $2^{-\Delta \Delta \mathrm{Ct}}$ method (the one expressing lowest miR-191 in tissue or cells was used as control) [15].

Western blot analysis. Cells were lysed on ice in radioimmunoprecipitation assay buffer (Thermo Fisher Scientific Inc., Waltham, Mass., USA). Total protein from cell extracts $(40 \mu \mathrm{g})$ was separated by $12 \%$ SDS-PAGE and transferred to PVDF membrane (Millipore, Bedford, MA, USA) using the Bio-Rad semidry transfer system. After blocking with milk, membranes were incubated overnight at $4^{\circ} \mathrm{C}$ with primary antibodies. After washed, membranes were then incubated with secondary antibodies for $1 \mathrm{~h}$ at room temperature. Two antibodies were used in this study: anti-TIMP3 (dilution 1: 400; Abcam, Cambridge, MA, USA) and anti-actin (dilution 1: 1,000; Abcam). Blotted proteins were detected using the ECL TM Plus Detection Kit (GE Healthcare, USA).

Gelatin zymography. To measure the activity of matrix metalloproteinase (MMP), cell lysates $(10 \mu \mathrm{l})$ were added to Zymogram sample buffer (Bio-Rad Laboratories, Hercules, CA, USA) and loaded on to $10 \%$ Novex Zymogram gels (Invitrogen). Following electrophoresis, gels were incubated in Zymogram renaturing buffer (Bio-Rad Laboratories) at room temperature for $30 \mathrm{~min}$ and then incubated in Zymogram development buffer (Bio-Rad Laboratories) at $37^{\circ} \mathrm{C}$ overnight with gentle shaking. After the gels were washed and stained in CoomassieBrillant Blue R-250 (Sigma-Aldrich, St. Louis, $\mathrm{MO}$, USA), quantification analysis was performed using the software program Image ( $\mathrm{NIH}$.

Luciferase miRNA target reporter assay. Total cDNA from HT29 cells was used to amplify the 3'untranslated regions (3'UTRs) of TIMP3 by PCR using the forward primers 5'-TCTTTGGAGGCGAGAGGAA-3' and the reverse primers 5'-CCACTTTACTGTTTAGAATAAAGGACAC-3'. Then, the fragment was cloned into the Spe I and Hind III sites downstream of luciferase gene in the pMIR-REPORT plasmid (Ambion) to generate pMir-Report-TIMP3 wt plasmid. Site-directed mutagenesis of miR-191 binding sites was carried out using a QuikChange site-directed mutagenesis kit (Stratagene, Santa Clara, CA, USA). The bases at the miR-191target region mutated from "AUUCCGU" to "UAAGGCA", abolishing its binding without affecting the reading frame. For reporter assays, HT29 and SW620 cells were transiently cotransfected with $0.3 \mu \mathrm{g}$ wt or mutant reporter plasmid and $60 \mathrm{nM}$ anti-miR-191 or anti-NC using lipofectamine 2000 (Invitrogen). After $24 \mathrm{~h}$, the cells were lysed. Luciferase activity was measured and normalized by the control vector containing Renilla luciferase.

Invasion assay. $48 \mathrm{~h}$ after transfection with either anti-miR191 or cotransfected with Anti-miR-191 and TIMP3 siRNA, SW620 cells were plated on the top of Matrigel-coated invasion chambers (24-well insert, 8 - $\mu \mathrm{m}$ pore size; BD Biosciences, San Jose, CA, USA) in a serum-free RPMI 1640 medium. As a chemoattractant, RPMI 1640 medium containing $10 \%$ fetal calf serum was added to the lower chamber. The cells were incubated for $24 \mathrm{~h}$, after which noninvaded cells were removed from the inner part of the insert. Cells on the lower surface of the membrane were fixed and stained using Hematoxylin and Eosine (Sigma-Aldrich) for visualization.

Proliferation assays. SW620 cells were seeded in 24-well plates $\left(5 \times 10^{4}\right.$ cells per well), in RPMI 1640 medium and after $24 \mathrm{~h}$, transfected with either anti-miR-191 or cotransfected with Anti-miR-191 and TIMP3 siRNA. Every 24 h, medium was replaced and cell counts were performed by using a CASY TT cell counter (Innovatis, Roche Applied Science).

Apoptosis assays. $1 \times 10^{6}$ cells were seeded in 6-well plates. 72 hours after transfection, the cells were harvested and stained with an Annexin V-FITC apoptosis detection kit (BD Biosciences, San Diego, CA) following the manufacturer's instruction. After incubation at room temperature for $15 \mathrm{~min}$, stained cells were analyzed by FACSCalibur flow cytometry (Becton Dickinson, USA).

Statistical analysis. Overall survival rates were analyzed by the Kaplan-Meier method and differences in survival rates were assessed by log-rank test. Correlation between clinicopathologic factors and miR-191 expression was estimated using the $\chi 2$ test. A Cox proportional hazards model was used for multivariate analysis. Other differences between groups were analyzed using Student's t test or repeated-measures ANOVA test. $P$ value $<0.05$ was defined as statistically significant.

\section{Results}

Relationship between miR-191 expression and clinicopathologic factors. The expression levels of miR-191 in the 
tumor from 136 patients were detected by Realtime PCR, using RNU6B as a control. CRC tissue samples with expression levels of miR-191 that were below the median value (11.676, normalized to RNU6B; range: 1-163) were assigned to the low expression group (mean expression value $6.855, \mathrm{n}=68$ ) and those samples with expression above the median value were assigned to the high expression group (mean expression value 39.986, $\mathrm{n}=68$ ). Relationship between miR-191 expression and clinicopathologic factors was analyzed (Table 1). Our results demonstrated that high expression of miR-191 was significantly correlated with advanced TNM stage, lymph node metastasis, liver metastasis and depth of tumor invasion $(p<0.05$, Table 1$)$. No significant differences were observed for other clinicopathologic features, including age, gender, tumor histology, lymphatic invasion, venous invasion and tumor size ( $p>0.05$, Table 1$)$.

Correlation between miR-191 expression and prognosis of patients with colorectal cancer. Overall survival curves of patients with low or high miR-191 mRNA expression level were plotted by Kaplan-Meier method and indicated that the survival rate was significantly lower in high miR-191 expression group compared to those in low expression group $(p<0.01$, Figure 1). Univariate analysis showed that four clinicopathological factors (histological grade, lymph node metastasis, liver metastasis and miR-191 expression) were significant prognosis factors (Table 2). Multivariate analysis of the four factors showed that miR-191 expression was a significant independent prognostic factor in colorectal cancer in addition to tumor histology and liver metastasis (Table 2).

TIMP3 is a target of miR-191. We first determined expression of miR-191 in 6 colorectal cancer cell lines, and found that HT29 and SW620 had the highest expressions of miR-191 in these cell lines (Fig 2A). To explore the mechanism linking miR-191 and poor prognosis in colorectal cancer, we used microRNA (microrna.org) to search the targets of miR-191. Combining with previous studies[16], we found that tissue inhibitor of metalloprotease 3 (TIMP3) gene was a possible one, which had a predicted binding site for miR-191 in the 3'UTR (Fig 2B). To validate that miR-191 can regulate TIMP3 mRNAs in colorectal cancer, luciferase reporter plasmids that contain predicted and mutated binding sites of TIMP3 3'UTR were constructed and luciferase activity in HT29 and SW620 cells were tested. Both HT29 and SW620 cells express high levels of endogenous miR-191, so anti-miR-191 was used to regulate the level of miR-191. The results showed that antimiR-191 significantly increased luciferase signals in SW620 cells compared with control anti-sense RNA (Fig 2C). The luciferase activity in HT29 cells transfected by miR-191 inhibitor was also increased compared with that transfected by control anti-sense RNA, but the difference was not significant (Fig 2B). The results indicated that TIMP3 was a direct miR-191 target, at least in SW620 cells. We then examined the protein levels of TIMP3 and found that it was upregulated by miR191 inhibition in both colorectal cancer HT29 and SW620 cells (Fig 2D).

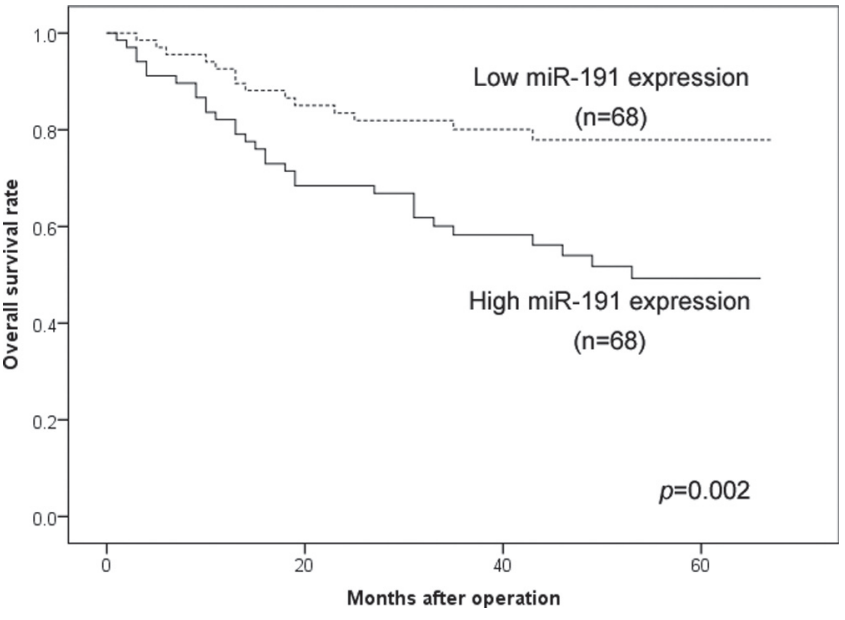

Figure 1. Kaplan-Meier survival curves of patients with colorectal cancer based on miR-191 expression. Patients with high miR-191 expression had significantly worse overall survival than those with low expression $(p<0.05)$.

Table 1. Correlation between clinicopathologic factors and miR-191 expression of colorectal cancer patients

\begin{tabular}{|c|c|c|c|}
\hline Variable & $\begin{array}{l}\text { Low expression } \\
\qquad(\mathrm{n}=68)\end{array}$ & $\begin{array}{l}\text { High expression } \\
\qquad(\mathrm{n}=68)\end{array}$ & $p$ value \\
\hline $\operatorname{Age}($ mean \pm SD $)$ & $67.8 \pm 6.85$ & $66.7 \pm 6.29$ & 0.343 \\
\hline Gender & & & 1.000 \\
\hline Male & 41 & 41 & \\
\hline Female & 27 & 27 & \\
\hline Histological grade & & & 0.452 \\
\hline well or mod & 50 & 46 & \\
\hline poor and other & 18 & 22 & \\
\hline TNM stage & & & $0.010^{*}$ \\
\hline I-II & 41 & 26 & \\
\hline III-IV & 27 & 42 & \\
\hline Lymph node metastasis & & & $0.0005^{*+x}$ \\
\hline Absent & 49 & 29 & \\
\hline Present & 19 & 39 & \\
\hline Lymphatic invasion & & & 0.335 \\
\hline Absent & 52 & 47 & \\
\hline Present & 16 & 21 & \\
\hline Venous invasion & & & 0.663 \\
\hline Absent & 56 & 54 & \\
\hline Present & 12 & 14 & \\
\hline Liver metastasis & & & $0.026^{*}$ \\
\hline Absent & 63 & 54 & \\
\hline Present & 5 & 14 & \\
\hline Size & & & 0.350 \\
\hline$<30 \mathrm{~mm}$ & 23 & 18 & \\
\hline$\geq 31 \mathrm{~mm}$ & 45 & 50 & \\
\hline Depth of tumor invasion & & & $0.040^{*}$ \\
\hline $\mathrm{T} 1, \mathrm{~T} 2$ & 40 & 28 & \\
\hline T3, T4 & 28 & 40 & \\
\hline
\end{tabular}

$\mathrm{SD}=$ Standard deviation, well $=$ well-differentiated adenocarcinoma; $\bmod$ $=$ moderately differentiated adenocarcinoma; por $=$ poorly differentiated adenocarcinoma. ${ }^{*} p<0.05,{ }^{* *} p<0.01,{ }^{* * *} p<0.001$. 


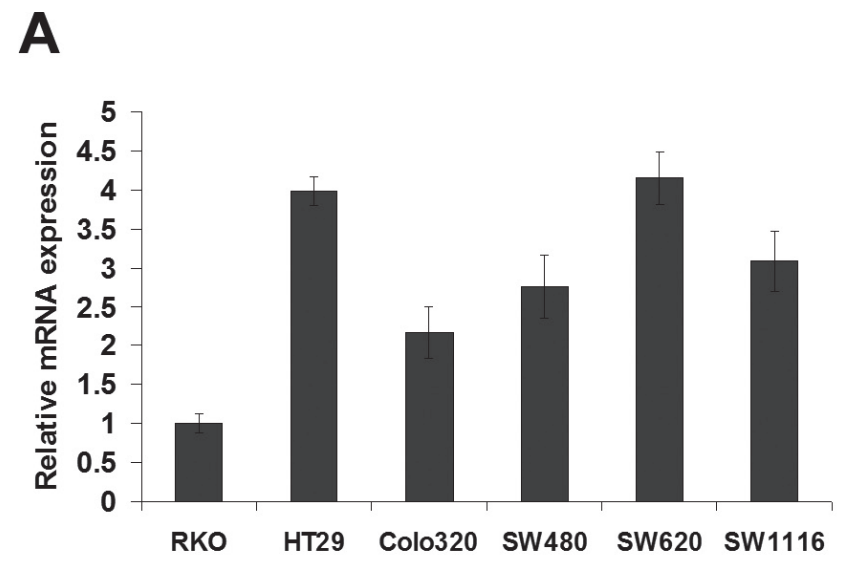

C

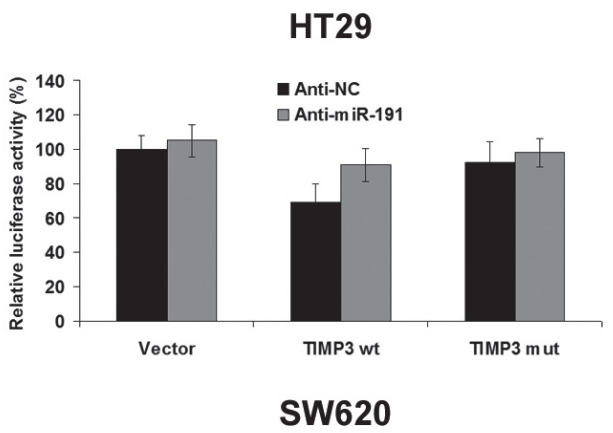

B
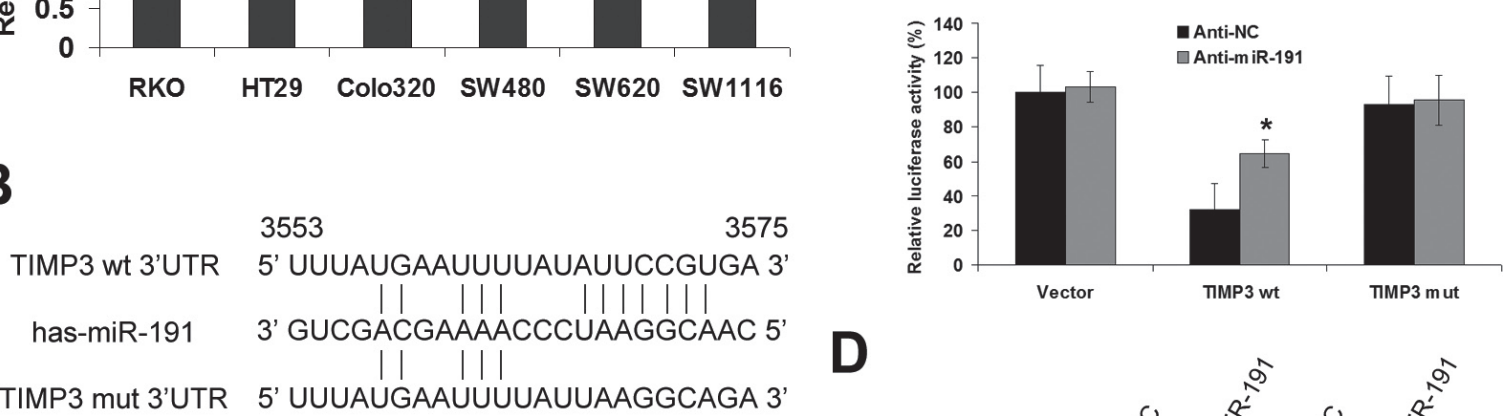

TIMP3 mut 3'UTR 5' UUUAUGAAUUUUAUUAAGGCAGA 3'

D

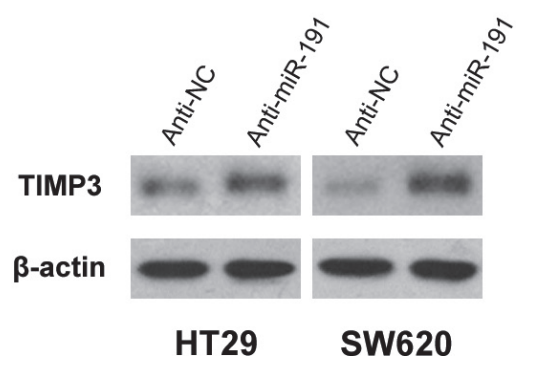

Figure 2. The TIMP3 3'-UTR is a target of miR-191. A, Realtime PCR analysis of miR-191 expression in 6 colorectal cancer cell lines. B, Predicted miR191 binding sites within TIMP3 3'-UTR and representation of the pMIR-TIMP3 vectors used in the Luciferase assay. The mutated miR-191 binding site (TIMP3 mut 3'-UTR) was also shown. C, pMIR-Report vectors containing the wild-type TIMP3 3'UTR (TIMP3 wt), or mutated TIMP3 3'UTR (TIMP3 mut) were transfected into HT29 and SW620 cells, that were then treated with either miR-191 inhibitor (Anti-miR-191) or control anti-sense RNA (anti-NC). The inhibition of miR-191 resulted in a significant increase in luciferase signals of TIMP3 wt transfected SW620 cells compared with antiNC. The effect of miR-191 inhibitor in HT29 was not significant. Data were from experiments performed in triplicate and represented as means \pm SEM. D, HT29 and SW620 cells were transfected with Anti-miR-191 and TIMP3 protein levels were detected by western blotting. ${ }^{*} p<0.05$ compared with control group.

Table 2. Univariate and multivariate analysis of clinicopathological factors for overall survival

\begin{tabular}{|c|c|c|c|c|c|c|}
\hline \multirow{2}{*}{ Variable } & \multicolumn{3}{|c|}{ Univariate analysis } & \multicolumn{3}{|c|}{ Multivariate analysis } \\
\hline & RR & $95 \% \mathrm{CI}$ & $\mathrm{p}$ value & $\mathrm{RR}$ & $95 \% \mathrm{CI}$ & $\mathrm{p}$ value \\
\hline $\operatorname{Age}(<65 / \geqq 65)$ & 0.884 & $0.504-1.550$ & 0.666 & - & - & - \\
\hline Gender(male/female) & 0.831 & $0.459-1.502$ & 0.539 & - & - & - \\
\hline Histological grade(well or mod/poor and other) & 2.486 & $1.383-4.469$ & $0.002^{\star *}$ & 2.407 & $1.274-4.547$ & $0.007^{\star *}$ \\
\hline Lymph node metastasis(negative/positive) & 2.934 & $1.592-5.410$ & $0.0006^{\star * *}$ & 1.793 & $0.913-3.519$ & 0.090 \\
\hline Lymphatic invasion(negative/positive) & 1.154 & $0.614-2.170$ & 0.656 & - & - & - \\
\hline Venous invasion(negative/positive) & 1.606 & $0.829-3.112$ & 0.160 & - & - & - \\
\hline Liver metastasis(negative/positive) & 2.362 & $1.193-4.678$ & $0.014^{*}$ & 2.199 & $1.069-4.519$ & $0.032^{*}$ \\
\hline $\operatorname{Size}(<30 \mathrm{~mm} / \geq 31 \mathrm{~mm})$ & 1.137 & $0.587-2.202$ & 0.703 & - & - & - \\
\hline Depth of tumor invasion(T1-T2/T3-T4) & 1.031 & $0.574-1.851$ & 0.919 & - & - & - \\
\hline miR-191 expression(low/high) & 2.592 & $1.378-4.874$ & $0.003^{\star *}$ & 2.033 & $1.045-3.957$ & $0.037^{\star}$ \\
\hline
\end{tabular}

$\mathrm{RR}=$ Relative risk; $\mathrm{CI}=$ confidence interval; well $=$ well differentiated adenocarcinoma; mod = moderately differentiated adenocarcinoma; por = poorly differentiated adenocarcinoma. ${ }^{*} p<0.05,{ }^{* *} p<0.01,{ }^{* * *} p<0.001$. 

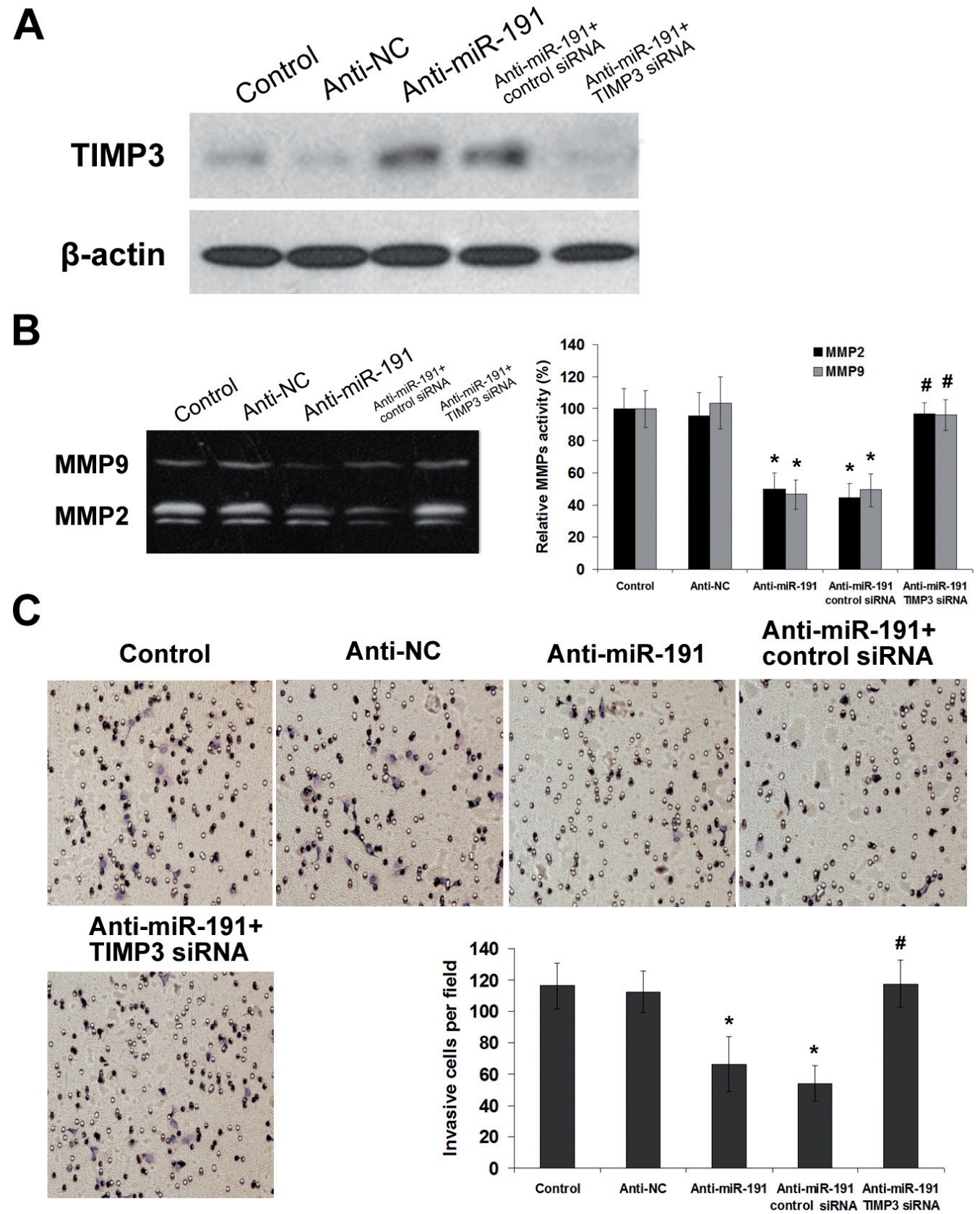

Figure 3. miR-191 inhibitor suppresses MMPs activity and invasion of SW620 cells. SW620 cells were transfected with miR-191 inhibitor (Anti-miR-191), control anti-sense RNA (anti-NC), or cotransfected with Anti-miR-191 and TIMP3 siRNA or control siRNA. A, The protein level of TIMP3 was detected by western blotting. Anti-miR-191 increased the protein expression of TIMP3 in SW620 cells, but TIMP3 siRNA inhibited the increase. B, The MMP-2 and MMP-9 activities were examined by gelatin zymography and intensity of the band was quantified. TIMP3 siRNA reversed the inhibition of MMP-2 and MMP-9 activities induced by anti-miR-191. The experiment was repeated three times and data were represented as means \pm SEM. C, Representative cell fields $(\times 100)$ of matrigel invasion assay and numbers of invasive cells. Anti-miR-191 suppressed the invasiveness of SW620 cells, but cotransfection of anti-miR-191 with TIMP3 siRNA rescued the invasiveness. The data obtained by counting average numbers of cells from nine different fields and represented as means \pm SEM. ${ }^{\star} p<0.05$ compared with control group, $\# p<0.05$ compared with Anti-miR-191 group.

Inhibition of miR-191 leads to down-regulation of MMP activities and reduction of invasiveness. Since TIMP3, a MMP inhibitor, correlates well with CRC cell motility and invasion[17], we examined the effects of miR-191 inhibition on
MMP proteolytic activities and CRC cell invasiveness. Western Blotting showed that cotransfection of anti-miR-191 and TIMP3 siRNA markedly decreased the protein level of TIMP3 compared with transfection of anti-miR-191 in SW620 cells 

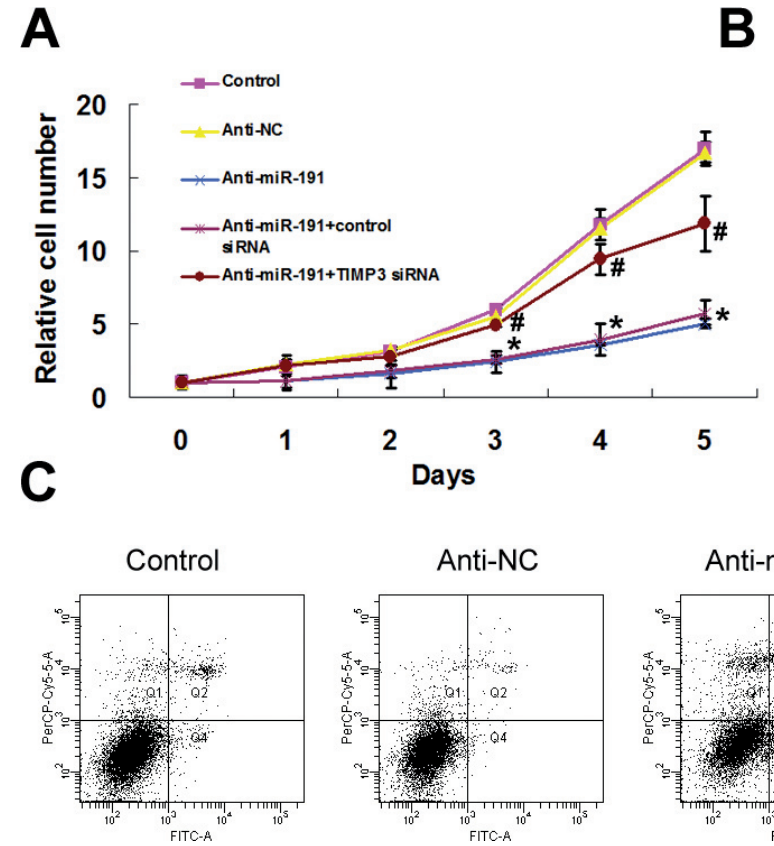
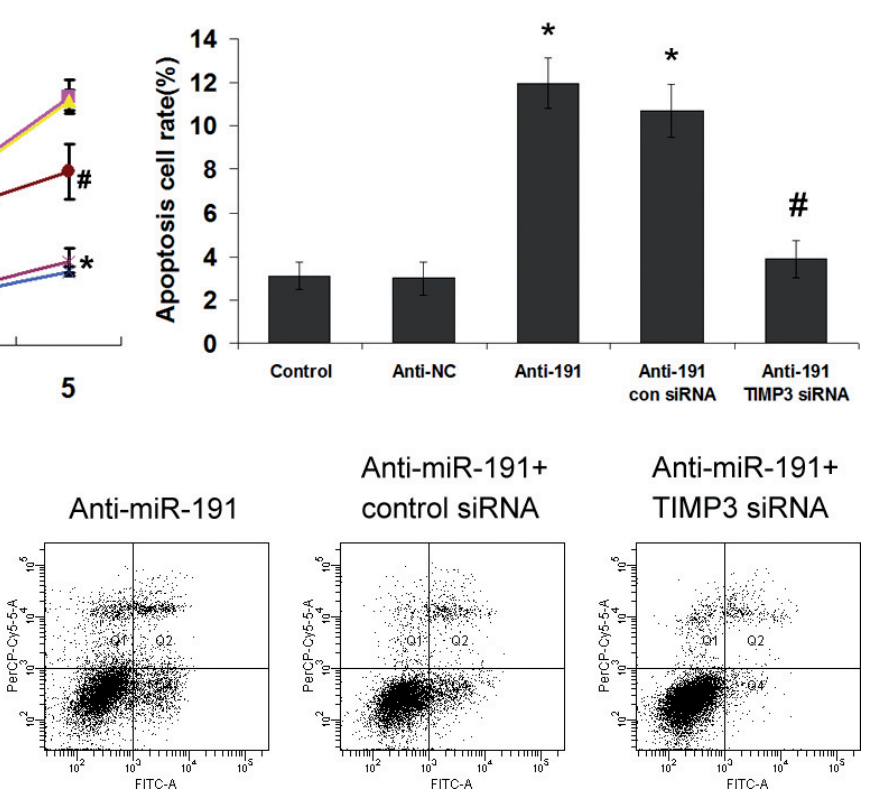

Figure 4. MiR-191 inhibitor suppressed proliferation and induced apoptosis of SW620 cells. SW620 cells were transfected with miR-191 inhibitor (AntimiR-191), control anti-sense RNA (anti-NC), or cotransfected with Anti-miR-191 and TIMP3 siRNA or control siRNA. A, Proliferation assays. MiR-191 inhibitor suppressed proliferation of SW620 cells, but TIMP3 siRNA recovered the proliferation. B, Cell apoptosis was examined by flow cytometry analysis of Annexin V/PI staining. Anti-miR-191 induced apoptosis of SW620 cells, but TIMP3 siRNA inhibited the apoptosis. C, Representative images of flow cytometry for cell apoptosis. The data obtained from repeated three wells and represented as means \pm SEM. ${ }^{\star} p<0.05$ compared with control group, \# $p<0.05$ compared with Anti-miR-191 group.

(Fig 3A). Gelatin zymography assay showed that anti-miR191 significantly reduced the levels of MMP-2 and MMP-9 proteolytic activity in SW620 cells compared with control (Fig 3B). TIMP3 siRNA reversed the reduction of MMPs activity induced by anti-miR-191 (Fig 3B), suggesting that miR-191 regulates MMPs activity through TIMP3.

We next studied the effects of miR-191 inhibition on CRC cell invasion using transwell invasion system. The numbers of invasive SW620 cells with inhibited miR-191 were significantly reduced compared with control (Fig 3C). Notably, this reduced-invasiveness was rescued by cotransfection of anti-miR-191 with TIMP3 siRNA (Fig 3C), indicating that TIMP3 is the major factor that mediates miR-191 function in SW620 cells invasion.

MiR-191 inhibitor suppresses proliferation and induces apoptosis. Besides MMP inhibition, TIMP3 relates to a number of cellular processes in cancer, such as cell proliferation and apoptosis [17]. So the effects of miR-191 and TIMP3 on cell proliferation and apoptosis in CRC cell were investigated. As shown in Figure 4A, cell proliferation was significantly inhibited by anti-miR-191 and was recovered by TIMP3 siRNA. Exposure of SW620 cells to anti-miR-191 for $72 \mathrm{~h}$ resulted in a significantly increase of apoptosis, whereas no obvious alterations of apoptosis rate were detected in cells treated with both anti-miR-191 and TIMP3 siRNA compared with control (Fig4B and C).

\section{Discussion}

Through binding to partially complementary sites, predominantly in 3'UTRs of mRNAs, miRNAs are involved in a variety of cellular activities and biological processes, including cancerogenesis $[18,19]$. The altered expressions of miRNAs in cancer tissues compared to normal tissues have been reported in many studies, suggesting the potential of these miRNAs as biomarkers[12, 20]. The identification of tumor-specific miRNAs and their target genes is crucial not only to validate underlying biological mechanisms in tumorgenesis, but also to provide potential targets for colorectal cancer therapy.

Overexpression of miR-191 has been observed in gastric carcinoma, hepatocellular carcinoma and colorectal carcinoma, implying its important role in tumorigenesis [12-14]. In this study, we found that high expression of miR-191 correlated with TNM stage as well as lymph node and liver metastasis, strongly suggesting that miR-191 might be involved in progression and metastasis of colorectal cancer. Moreover, Kaplan-Meier analysis of overall survival showed that patients with higher miR-191 expression tend to have significantly worse prognosis, and in support of this, Cox proportional hazards model showed that miR-191 was an independent prognostic factor in CRC.

MiRNAs can regulate the expression of multiple mRNA targets and thereby change several cellular programs. Nine 
HT29

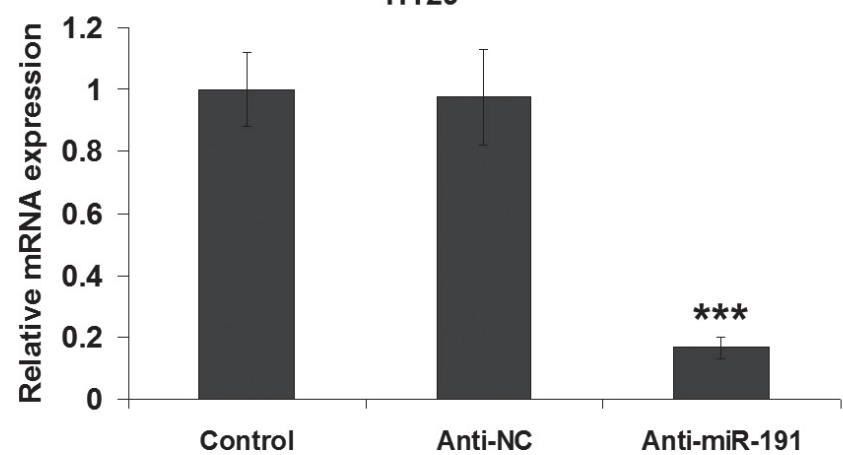

SW620

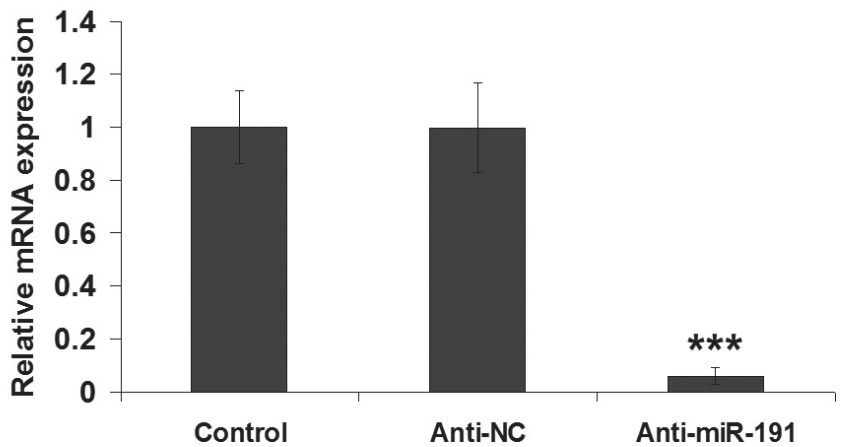

Figure S1. Anti-miR-191 inhibits miR-191 expression. Realtime PCR analysis for miR-191 expression in HT29 and SW620 cells. Data were from experiments performed in triplicate and represented as means \pm SEM. ${ }^{* * *} p<0.001$ compared with control group.

candidate target genes of miR-191 have been identified in hepatocellular carcinoma[16], and $\mathrm{N}$-deacetylase/ $\mathrm{N}$-sulfotransferase 1 (NDST1) was confirmed to be a direct target gene of miR-191 in gastric cancer[14]. Here, we demonstrated that a target of miR-191 in CRC was TIMP3, which was also a candidate target gene of miR-191 in hepatocellular carcinoma [16]. TIMP3 is a member of tissue inhibitors of metalloproteinases (TIMP), which are the key inhibitors of MMPs [17]. Down-regulated TIMP3 was observed in many malignant tumors including colorectal cancer [21-23]. Although hypermethylation of the TIMP3 gene promoter may contribute to silencing of the TIMP3 gene expression [22], the present study suggests miR-191-mediated gene inhibition is an alternative regulatory mechanism. Interestingly, luciferase assay showed that TIMP3 was not the direct target of miR-191 in HT29 cells. One possible reason is that HT29 and SW620 cells came from different areas of tumor tissues and had different mechanisms of tumorigenesis [24].

MMPs are critical molecules assisting tumor cells metastasis and up-regulation of MMPs usually led to enhanced tumor cell invasion $[25,26]$. Inhibition of miR-191 decreased MMP activities and moreover, it led to reduction of SW620 cells invasion, which was rescued by TIMP3 siRNA. This implied that miR-191 regulated TIMP3 expression and thus MMP activities and CRC invasiveness. The evidences developed over the years support the role of TIMPs in regulating cell proliferation and apoptosis and these effects appear to be cell-type specific and sometimes are results of MMP-independent mechanisms [17]. Our data from proliferation and apoptosis assays showed that anti-miR-191 blocked proliferation and induced apoptosis of SW620 cells through restoring TIMP3 expression. The increased apoptosis induced by anti-miR-191 could partly explain the suppression of proliferation. These results mean that miR-191 plays multiple roles in CRC progression by targeting TIMP3. Whether TIMP3 regulates proliferation and apoptosis in CRC cells through pathways independent of MMP deserves further investigation.

In conclusion, we demonstrated that miR-191 expression was associated with metastasis of CRC and miR-191 was a novel independent prognostic factor of patients with CRC. Furthermore, miR-191 contributed to CRC malignancy by downregulation of TIMP3. Our results suggested that miR191 may be a potential diagnostic and therapeutic target in patients with colorectal cancer.

\section{References}

[1] JEMAL, A., R. SIEGEL, E. WARD, Y. HAO, J. XU, et al., Cancer Statistics, 2009. CA: A Cancer Journal for Clinicians. 2009; 59: 225-249. http://dx.doi.org/10.3322/caac.20006

[2] GUO, P., Z.L. HUANG, P. YU, and K. LI, Trends in cancer mortality in China: an update. Annals of Oncology 2012; 23: 2755-2762. http://dx.doi.org/10.1093/annonc/mds069

[3] MANFREDI, S., C. LEPAGE, C. HATEM, O. COATMEUR, J. FAIVRE, et al., Epidemiology and management of liver metastases from colorectal cancer. Ann Surg 2006; 244: 254-9. http://dx.doi.org/10.1097/01.sla.0000217629.94941. cf

[4] SOBIN LH, W.C., ed. TNM classification of malignant tumors. fifth edition ed., ed. I.U.A.C. (UICC). 1997, John Wiley \& Sons, Inc.: New York.

[5] PENG, Y., X. LI, M. WU, J. YANG, M. LIU, et al., New prognosis biomarkers identified by dynamic proteomic analysis of colorectal cancer. Molecular BioSystems 2012; 8: 3077-3088. http://dx.doi.org/10.1039/c2mb25286d

[6] LAGES, E., H. IPAS, A. GUTTIN, H. NESR, F. BERGER, et al., MicroRNAs: molecular features and role in cancer. Front Biosci 2012; 17: 2508-40. http://dx.doi.org/10.2741/4068

[7] WALDMAN SA, T.A., TRanslating microrna discovery into clinical biomarkers in cancer. JAMA: The Journal of the American Medical Association 2007; 297: 1923-1925. http:// dx.doi.org/10.1001/jama.297.17.1923

[8] ZHOU, T., G. ZHANG, Z. LIU, S. XIA, and H. TIAN, Overexpression of miR-92a correlates with tumor metastasis and poor prognosis in patients with colorectal cancer. International Journal of Colorectal Disease 2012: p. 1-6.

[9] YAMASHITA, S., H. YAMAMOTO, K. MIMORI, N. NISHIDA, H. TAKAHASHI, et al., MicroRNA-372 is associated 
with poor prognosis in colorectal cancer. Oncology 2012; 82: 205-12.

[10] AKCAKAYA, P., S. EKELUND, I. KOLOSENKO, S. CARAMUTA, D.M. OZATA, et al., miR-185 and miR-133b deregulation is associated with overall survival and metastasis in colorectal cancer. Int J Oncol 2011; 39: 311-8.

[11] XI, Y., A. FORMENTINI, M. CHIEN, D.B. WEIR, J.J. RUSSO, et al., Prognostic Values of microRNAs in Colorectal Cancer. Biomark Insights 2006; 2: 113-121.

[12] VOLINIA, S., G.A. CALIN, C.-G. LIU, S. AMBS, A. CIMMINO, et al., A microRNA expression signature of human solid tumors defines cancer gene targets. Proceedings of the National Academy of Sciences of the United States of America 2006; 103: 2257-2261. http://dx.doi.org/10.1073/ pnas.0510565103

[13] ELYAKIM, E., E. SITBON, A. FAERMAN, S. TABAK, E. MONTIA, et al., hsa-miR-191 Is a Candidate Oncogene Target for Hepatocellular Carcinoma Therapy. Cancer Research 2010; 70: 8077-8087. http://dx.doi.org/10.1158/0008-5472. CAN-10-1313

[14] SHI, X., S. SU, J. LONG, B. MEI, and Y. CHEN, MicroRNA-191 targets $\mathrm{N}$-deacetylase/ $\mathrm{N}$-sulfotransferase 1 and promotes cell growth in human gastric carcinoma cell line MGC803. Acta Biochimica et Biophysica 2011; 43: 849-856.

[15] LIVAK, K.J. and T.D. SCHMITTGEN, Analysis of Relative Gene Expression Data Using Real-Time Quantitative PCR and the 2- $\Delta \Delta$ CT Method. Methods 2001; 25: 402-408. http:// dx.doi.org/10.1006/meth.2001.1262

[16] HE, Y., Y. CUI, W. WANG, J. GU, S. GUO, et al., Hypomethylation of the hsa-miR-191 locus causes high expression of hsa-mir-191 and promotes the epithelial-to-mesenchymal transition in hepatocellular carcinoma. Neoplasma, 2011; 13: 841-53.

[17] CRUZ-MUNOZ, W. and R. KHOKHA, The Role of Tissue Inhibitors of Metalloproteinases in Tumorigenesis and Metastasis. Critical Reviews in Clinical Laboratory Sciences, 2008; 45: 291-338. http://dx.doi. org/10.1080/10408360801973244
[18] BARTEL, D.P., MicroRNAs: Target Recognition and Regulatory Functions. Cell 2009; 136: 215-233. http://dx.doi. org/10.1016/j.cell.2009.01.002

[19] KWAK, P.B., S. IWASAKI, and Y. TOMARI, The microRNA pathway and cancer. Cancer Science, 2010; 101: 2309-2315. http://dx.doi.org/10.1111/j.1349-7006.2010.01683.x

[20] HAN, Z.-B., H.-Y. CHEN, J.-W. FAN, J.-Y. WU, H.-M. TANG, et al., Up-regulation of microRNA-155 promotes cancer cell invasion and predicts poor survival of hepatocellular carcinoma following liver transplantation. Journal of Cancer Research and Clinical Oncology 2012; 138: 153-161. http:// dx.doi.org/10.1007/s00432-011-1076-Z

[21] LIN, H., Y. ZHANG, H. WANG, D. XU, X. MENG, et al., Tissue inhibitor of metalloproteinases-3 transfer suppresses malignant behaviors of colorectal cancer cells. Cancer Gene Ther, 2012. http://dx.doi.org/10.1038/cgt.2012.70

[22] GU, P., X. XING, M. TANZER, C. ROCKEN, W. WEICHERT, et al., Frequent loss of TIMP-3 expression in progression of esophageal and gastric adenocarcinomas. Neoplasma 2008; 10: $563-72$.

[23] SHINOJIMA, T., Q. YU, S.K. HUANG, M. LI, R. MIZUNO, et al., Heterogeneous epigenetic regulation of TIMP3 in prostate cancer. Epigenetics 2012; 7: 1279-89. http://dx.doi. org/10.4161/epi.22333

[24] O`CONnEll, J., M.W. BennetT, K. NALLY, G.C. O'SULLIVAN, J.K. COLLINS, et al., Interferon- $\gamma$ sensitizes colonic epithelial cell lines to physiological and therapeutic inducers of colonocyte apoptosis. Journal of Cellular Physiology 2000; 185: 331-338. http://dx.doi.org/10.1002/ 1097-4652(200012)185:3<331::AID-JCP3>3.0.CO;2-V

[25] DERYUGINA, E. and J. QUIGLEY, Matrix metalloproteinases and tumor metastasis. Cancer and Metastasis Reviews 2006; 25: 9-34. http://dx.doi.org/10.1007/s10555-006-7886-9

[26] ZHANG, Y., X.-Y. GUAN, B. DONG, M. ZHAO, J.-H. WU, et al., Expression of MMP-9 and WAVE3 in colorectal cancer and its relationship to clinicopathological features. Journal of Cancer Research and Clinical Oncology 2012; 138: 2035-2044. http://dx.doi.org/10.1007/s00432-012-1274-3 